\title{
INFLUENCE OF COMBINED HYGRO-THERMOMECHANICAL TREATMENT ON TECHNICAL CHARACTERISTICS OF POPLAR WOOD
}

\author{
Reza Hajihassani ${ }^{1}$, Behbood Mohebby ${ }^{1, \star}$, Saeed Kazemi Najafi, Parviz Navi ${ }^{2}$
}

\begin{abstract}
Combined hygro-thermo-mechanical technique was adopted and used for densification of poplar wood instead of sole treatment. This technique is combination of two techniques of hygrothermal treatment and densification of wood. For treatment, poplar wood blocks were initially treated hygrothermally at temperatures of 130,150 and $170^{\circ} \mathrm{C}$ for holding time of 20,40 minutes. Afterwards, the densification process was carried out under a hot press (temperature $160^{\circ} \mathrm{C}$ for 20 minutes). For densification compression set was adjusted for 40 and $60 \%$ based on the initial thickness (radial direction) of the blocks. The densified and non-densified wood blocks were tested for physical and mechanical properties as density, water absorption, thickness swelling, springback, bending strength, modulus of elasticity as well as shear strength parallel to grain. Results revealed that wood properties were enhanced due to the combined hygro-thermo-mechanical -treatment. According to the results, wood density was increased due to the combined hygro-thermo-mechanical -treatment significantly. The treatment improved the dimensional stability of the densified samples. It was also found that the combined hygro-thermo-mechanical -treatment could significantly improve mechanical properties and also reduce the springback in the densified poplar wood.
\end{abstract}

Keywords: Compression set, hygrothermal treatment, mechanical properties, physical properties, Populus deltoides, wood densification.

\section{INTRODUCTION}

Wood as a natural composite biopolymer has some unique advantages for industrial applications; such as easy access, appropriate ecological assessment, high strength/weight ratio, flexibility, easy processing, lightness, reusability, renewability, environmental compatibility, etc. Beside the advantages, it has also some disadvantages which are not all due to varying natural conditions where the trees have grown before. There are some technological limiting factors for application of the wood for structural purposes; such as moisture absorption, dimensional instability, biodegradation, photodegradation as well as weathering. Therefore, this natural material may need to be transformed in order to achieve the desired functionality (Navi and Sandberg 2011). Thermal wood modification could be a choice to achieve those goals.

Hydro- and hygro-thermal treatment of the wood are categorized as thermal wood modification techniques in aqueous medium (steam and water). Wood properties are enhanced due to those techniques according to earlier reports (Navi and Sandberg 2011). Some reports indicated that

\footnotetext{
${ }^{1}$ Department of Wood and Paper Sciences, Faculty of Natural Resources, Tarbiat Modares University, Noor, Iran.

${ }^{2}$ Department Of Architecture, Wood and Civil Engineering, Bern University of Applied Sciences, Bern, Switzerland.

"Corresponding author: mohebbyb@modares.ac.ir
}

Received: 25.09.2016 Accepted: 30.10.2017 
combination of hydro- and hygro-thermal treatments with other modification techniques which provides high performance properties with combination of both techniques in the wood; such CHTM and THM (Mohebby and Sanaei 2005). The CHTM stands for combined-hydro-thermo-mechanical modification which is a method with combination of hydro-thermal wood modification and mechanical wood modification (densification) techniques (Mohebby and Sanaei 2005) and the THM also stands for hydro-thermo-mechanical wood modification which is specified for densification of wood under water steam (Navi and Heger 2004).

Those processes are generally divided into two main groups: hydro-thermal (TH) and hydrothermo-mechanical (THM) treatments. The TH treatment is based on water and heat, and the THM applies an additional mechanical force as well. In addition, these processes consume comparatively a little energy. The results of studies in different fields of THM/TH processes showed that wood properties; such as dimensional stability, strength, hardness and durability are improved due to the treatment (Navi and Sandberg 2011). By TH processes, the reactions related to wood chemical structure changes and hydrolysis of wood cell wall polymers carry out at elevated temperatures $\left(160-240^{\circ} \mathrm{C}\right)$, pressures $(1-3,5 \mathrm{MPa})$ and holding time from a few minutes to several hours with solid concentration below 20 wt.\% (Alvira et al. 2010). During the TH process, hydrolysis of lignocellulosic linkages are occurred due to formation of the hydronium ions; which are generated from water hydrolysis. In other words, liquid water changes to hydronium ions at high temperatures which act as an acid and hydrolyze wood polysaccharides. The hydronium ions increase de-acetylation and hydrolysis reactions in cell wall polymers (Liu 2008). As the process is environmental friendly, there are no worries about harmful materials, corrosion of tools and also chemicals recovery (Garrote et al. 1999) as well as the environmental impacts. In addition to changes in the physical properties; such as dimensional stability, the hydrothermal treatment causes loss in mechanical characteristics due to reduction of wood density. It is known that the mechanical properties of wood is correlated with the density.

Wood densification is an effective mechanical modification technique to increase the density (Stamm 1964). Therefore, another new and emerging eco-friendly method has also been reported as combined of temperature, moisture and mechanical actions, which is so-called thermo-hydromechanical treatment (Kutnar et al. 2008, Mohebby and Sanaei 2005, Inoue et al. 1993, Boonstra and Blomberg 2007, Navi and Girardet 2000, Navi and Heger 2004, Fukuta et al. 2007, Dwianto et al. 1999, Ito et al. 1998). The products manufactured by hydro-thermo-mechanical treatment have higher density and improved mechanical properties (Kutnar et al. 2008, Mohebby and Sanaei 2005, Blomberg 2005, Dwainto et al. 1997, 1999), bioresistance (Hakkou et al. 2005, Boonstra et al. 2007), low equilibrium moisture content (Metsa-Kortelainen et al. 2006), improved dimensional stability (Esteves et al. 2007, Inoue et al. 1993, Hillis 1984, Hsu et al. 1988) and more hydrophobic effect (Mohebby and Sanaei 2005, Tjeerdsma and Militz 2005, Welzbacher et al. 2008). This method is also improved wood strength and stiffness, which is suitable for species with low-densities like poplar (Mohebby and Sanaei 2005, Gong et al. 2010).

Hydrothermal treatment can affect and change hydroxyl $(\mathrm{OH})$ and carbonyl $(\mathrm{C}=\mathrm{O})$ groups of cellulose, hemicellulose and lignin (Popescu and Popescu 2013). Steam treatment of the wood (hygrothermal treatment) eliminates acetyl groups of the hemicelluloses by using the acetic acid production. Acidic hydrolysis of cell wall polysaccharides produce water-soluble monosaccharide (arabinose, galactose, glucose, xylose and mannose) (Ramos 2003, Lam 2011). The presence of acetic acid derived from hemicellulose is also a factor for high lignin degradation. During the hydrothermal process of softwood, destruction B-O-4 linkages in lignin structure is the main reason for reduction of wood hardness (Assor et al. 2009). Renovated lignin improves resistance to failure in treated samples. The modified lignin also improves treated wood resistance to water absorption (Biswas et al. 2011, Lam et al. 2011).

Effects of the densification as well as the heat treatment have been evaluated on aspen wood. Densified surface of aspen which was heat-treated at temperatures between $190-210^{\circ} \mathrm{C}$ had a lower density than that of those with no heat-treatment. However, the moderate density was still higher than the non-treated and non-densified wood. The thickness swelling of compressed aspen wood after heattreatment reduced from 32 to $9 \%$ in the radial direction. The surface hardness and nail withdrawal 
resistance had reduction of 33 and $37 \%$, respectively compared with the unheat-treated densified aspen wood. The heat-treatment has also negative effect on MOE and reduces its values by 24 and $32 \%$ in densified and non-densified wood, respectively (Gong et al. 2010).

As above mentioned, Mohebby et al. (2009) introduced the combined hydro-thermo-mechanical treatment (CHTMT). According to their report, poplar wood was initially treated hydrothermally (at temperatures of 120,150 , and $180^{\circ} \mathrm{C}$ for holding time of 0,30 , and 90 minutes). Afterwards, the treated samples were compressed by a hot press $\left(160\right.$ and $180^{\circ} \mathrm{C}$ for 20 minutes) with a compression set of $60 \%$. By this technique, springback was reduced in densified wood. Results also indicated that the hydrothermal treatment temperature is much more effective than that of the press temperature. Changes in chemical structure of the wood; such as hemicelluloses destruction, increased cellulose crystallinity as well as more cross-linking in lignin polymer and also hydrophobicity of the wood, hemicellulose elimination and limitation of hydroxyl groups are the reasons, for reduction of the springback, reduction of thickness swelling, increase of anti-swelling-efficiency (ASE) in CHTM-treated wood. In addition, this research showed that the CHTM-treatment increased mechanical strength (bending modulus of rupture and modulus of elasticity, impact strength and hardness) of the CHTM-treated wood.

Welzbacher et al. (2008) densified pine specimens at four temperatures in combination with four press times and then heat-treated the densified wood in oil at three levels of temperature for 2 and 4 hours. The compression ratio used varied from about 40 to $50 \%$. Results showed that the densified dimension was almost completely stabilized in those specimens that were oil-treated at temperatures above $200^{\circ} \mathrm{C}$.

Swelling behavior and mechanical properties of compressed Japanese cedar have been studied by Anshari et al. (2011). The results showed that the maximum swelling stress was in radial direction. However, in the tangential direction, the swelling stress was decreased with increasing of the compression ratio. In fact, moisture-dependent dimensional behavior was changed in the radial and tangential direction and also obtained material properties provided structural changes in wood. Moreover, by increasing of compression ratio, corresponding densities are also increased in comparison with the initial density of treated wood, which is a reason for improvement of the mechanical properties.

According to the noticed reports, there are different techniques which are used to densify wood. However, most of them had less success in reduction of springback in the densified wood. Previous work dealing with the combined-hydro-thermo-mechanical treatment showed great influence on the densified wood springback (Mohebby and Sanaei 2005). In the current work, a similar technique has been used for densification of poplar wood. However, the densification technique was combined with the hygrothermal wood modification instead of the hydrothermal technique to understand whether this combined technique is capable of reducing the springback as well as to know any effects on mechanical properties of the densified wood.

\section{MATERIALS AND METHODS}

Wood specimens, $50 \times 50 \times 500 \mathrm{~mm}$, were prepared from fresh flat sawn poplar wood (Populus deltoides) and soaked in water for $24 \mathrm{~h}$ prior to treatment. Afterwards, the specimens were placed in a stainless steel steaming cylinder and treated at temperatures of 130,150 , and $170^{\circ} \mathrm{C}$ for holding time of 20 and 40 minutes (holding time refers to the time that the specimens were treated at a constant temperature after achieving the target treatment temperature). Before the compression process and due to the high moisture content (MC) of the samples, the hygro-thermally treated samples were initially air-seasoned to reduce the moisture content and then oven-dried at temperature of $60^{\circ} \mathrm{C}$ to achieve MC $15 \%$. The hygrothermally treated wood specimens were then placed in a hot press and compressed in the radial direction (thickness) at press temperatures of $160^{\circ} \mathrm{C}$ for 20 minutes with a compression set of 40 and $60 \%$ and the pressure 55 bar (Mohebby and Sanaei 2005). At least 10 samples were treated for each treatment. 
The mechanical (bending and shear) strength of the treated and the untreated wood samples were determined according to ASTM D 143-09 (2014). Density, water absorption, thickness swelling as well as springback of the densified and non-densified samples. The bending moduli of rapture and elasticity (with the span length/depth ratio of 15) and also shear strength parallel to grain were carried out by Dartec universal testing machine.

The water absorption and thickness swelling parameters of the oven dried samples were evaluated as follows. The specimens were soaked in water for 24,48 and $72 \mathrm{~h}$. The weight and dimensions were measured prior to and after soaking in water. The water absorption and the thickness swelling were calculated according to Equation 1 and Equation 2:

$$
W_{A}=\frac{M w-M_{0}}{M_{0}}
$$

Where $W_{A}$ is water absorption (\%), $M_{w}$ is weight after soaking in water (g) and $M_{0}$ is weight after oven-drying (g).

$$
T S=\frac{T_{1}-T_{O}}{T_{O}} \times 100
$$

Where $T_{S}$ is thickness swelling (\%), $T_{1}$ is thickness after soaking in water ( $\mathrm{mm}$ ) and $T_{0}$ is thickness after oven-drying (mm).

The springback of the densified specimens was immediately calculated after press (densification). Afterwards, these samples were conditioned at $25 \pm 2^{\circ} \mathrm{C}$ temperature and of $65 \pm 5 \%$ relative humidity for 4 weeks after densification to determine the springback once again according to Equation 3:

$$
S_{t}=\frac{h_{2}-h_{1}}{h_{1}} \times 100
$$

Where $S_{t}$ is springback rate (\%), $h_{1}$ is final thickness under press $(\mathrm{cm})$ and $h_{2}$ is thickness after press and conditioning $(\mathrm{cm})$.

The obtained data from the tests were statistically analyzed based on a complete randomized design (CRD) under factorial experiment and the mean values were then grouped according to Duncan's multiple range test (DMRT).

\section{RESULTS AND DISCUSSION}

\section{Density}

The hygrothermal treatment (HTT) affected the wood density in the poplar wood as shown in Figure 1. Any increase of the treatment temperature as well as the holding time reduced the wood density. Densification of the wood based on the compression sets (C.S.) of 40 and $60 \%$ has also increased the 
wood density in the control samples as shown in Figure 2. The density of control samples of the poplar wood was about $0,46 \mathrm{~g} / \mathrm{cm}^{3}$ (Figure 1); while it was $0,67 \mathrm{~g} / \mathrm{cm}^{3}$ for the C.S. $40 \%$ and $0,85 \mathrm{~g} / \mathrm{cm}^{3} \mathrm{~m}$ for the C.S. $60 \%$ (Figure 2). Combination of the hygrothermal treatment and the densification process (mechanical modification) (CHTMT) increased the wood density by $146 \%$ and $180 \%$ for C.S. $40 \%$ and C.S. $60 \%$, respectively (Figure 2). In the CHTMT wood, any increase of the treatment temperature reduced the density. However, the reduction rate of the density was much less in the CHTMT wood than that of the HTT wood. The holding time has also affected the density in the CHTMT wood as shown in Figure 2. However, the rate was much less than that of the HTT wood. Similarly the density was increased by compression set (Figure 2). According to the reports, the reason for density loss in the HTT wood deals with the mass loss due to the hydrothermal treatment (Mohebby and Sanaei 2005, Mirzaei et al. 2012). Here, the hygro-thermo-mechanical treatment has also showed similar action as the hydrothermal one. The reports indicated that formation of hydronium ions at high temperatures and holding time initiates hydrolysis of wood polysaccharides with following cleavage of the molecular bonds and cross-linking reactions (Liu 2008).

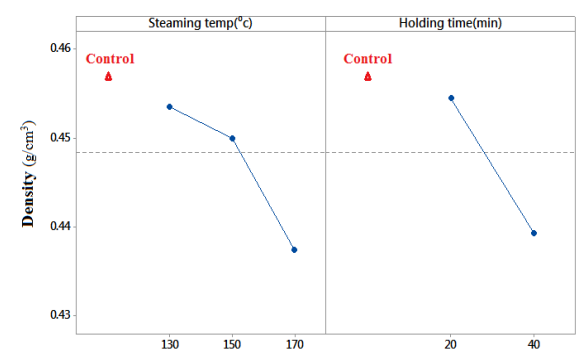

Figure 1. Main effect of hygrothermal treatment temperature and holding time on density in HTT process

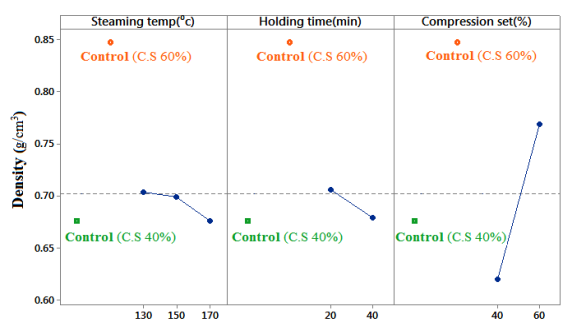

Figure 2. Main effect of hygrothermal treatment temperature, holding time and compression set on density in CHTMT process

Increasing the density due to the CHTMT is related to the densification process in wood that has caused increase of the mass vs the reduction in the wood volume. Any increase of the density in the CHTMT wood was greater than that of the non-densified control samples and the wood achieved the density of the densified control samples with the C.S. of $40 \%$ (Figure 1 and Figure 2). Mass loss due to the hygrothermal treatment might be the reason why the CHTMT wood could not achieve the C.S. of $60 \%$ in the densified control samples. The mass loss of the cell wall structures due to reactions is related to chemical changes and hydrolysis of the cell wall polymers during the hygrothermal treatment (Alvira et al. 2010) which are responsible for limited increase of the density by compression set.

\section{Water absorption \& Thickness swelling}

As indicated in the Table 1, the treatment temperature as well as the compression set showed significant effects on the water absorption and the radial swelling of the CHTMT treated wood. However, the holding time had no significant effect on the noticed properties. There was only significant effect on the water absorption as well as the radial thickness swelling for interactions between the treatment temperature and the holding time. 
Table 1. Summarized results of ANOVA for water absorption and thickness swelling in CHTM treated poplar wood.

\begin{tabular}{|c|c|c|c|c|c|c|c|}
\hline & & \multicolumn{3}{|c|}{ Water absorption (\%) } & \multicolumn{3}{|c|}{ Thickness swelling (\%) } \\
\hline & & 24 hours & 48 hours & 72 hours & 24 hours & 48 hours & 72 hours \\
\hline \multirow{3}{*}{ Main effect } & $\mathrm{T}$ & $*$ & ** & ** & $*$ & $*$ & $*$ \\
\hline & $\mathrm{H}$ & ns & ns & Ns & ns & $*$ & $*$ \\
\hline & $\mathrm{C}$ & $*$ & $*$ & $*$ & $*$ & $*$ & * \\
\hline \multirow{4}{*}{ Interaction effect } & $\mathrm{T} \times \mathrm{H}$ & $*$ & * & * & $*$ & $*$ & $*$ \\
\hline & $\mathrm{T} \times \mathrm{C}$ & ns & ns & Ns & * & ns & ns \\
\hline & $\mathrm{H} \times \mathrm{C}$ & ns & ns & Ns & ns & ns & ns \\
\hline & $\mathrm{T} \times \mathrm{H} \times \mathrm{C}$ & ns & ns & Ns & ns & ns & ns \\
\hline
\end{tabular}

T: Hygrothermal temperature, H: Holding time, C: compression set, *: Significant at above $99 \%$ of the confidence level, **: Significant at $95 \%$ of the confidence level, ns: Insignificant

As shown in Figure 3 and Figure 4, the water absorption and the radial swelling of the CHTMT wood were reduced by increase of the treatment temperature as well as the holding time after 24 and 72 hours of soaking in water. However, the reduction for those parameters was negligible for the holding time. Any increase of the compression set caused increase of the water absorption and the radial swelling of the CHTMT and untreated densified wood as shown in Figure 3 and Figure 4. The results revealed that influence of the treatment temperature was much effective when the temperature raises from $130^{\circ} \mathrm{C}$ up to $170^{\circ} \mathrm{C}$.

According to the results, rate of increase for the water absorption and the radial swelling are very similar for the untreated densified wood and the CHTMT treated wood when the compression set increases from 40 to $60 \%$. However, the amount of the radial swelling for the CHTMT wood, when it is densified up to C.S. $60 \%$, which is less than that of the untreated densified samples with the same compression set (Figure $4 \mathrm{a}$ and Figure $4 \mathrm{~b}$ ).

There are previous works which are indicating the dominant effect of the treatment temperature on water absorption and the swelling in comparison with the holding time (Mohebby and Sanaei 2005). According to the reports, that has been noticed above that the temperature initiates the reactions between the cell wall polymers followed by formation of hydronium ions, cleavages and cross-linking reaction in the lignin and celluloses polymers, degradation of the hemicelluloses as well as reduction in the hydroxyl groups in the cell wall polymers (Biswas et al. 2011, Mohebby and Sanaei 2005, Alvira et al. 2010, Navi and Sandberg 2011, Lam et al. 2011, Boonstra and Tjeerdsma 2006, Blomberg 2005, Navi and Girardet 2000). Therefore, they could be known as the main reasons for reduction of the water absorption and the swelling in the CHTMT treated wood. Presence of great mass per volume might be the reason for increase of the water absorption and the radial swelling in the untreated densified wood as well as the CHTMT wood samples compressed up to C.S. of $60 \%$. 


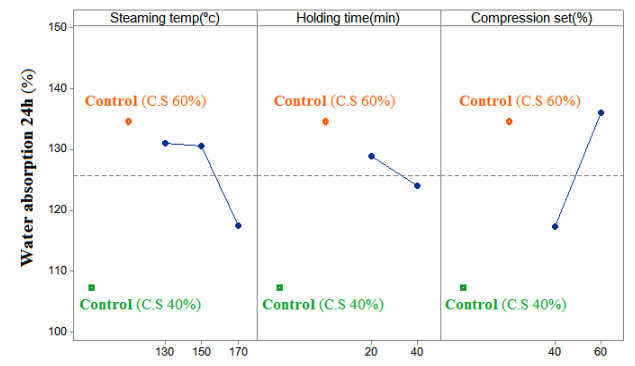

a

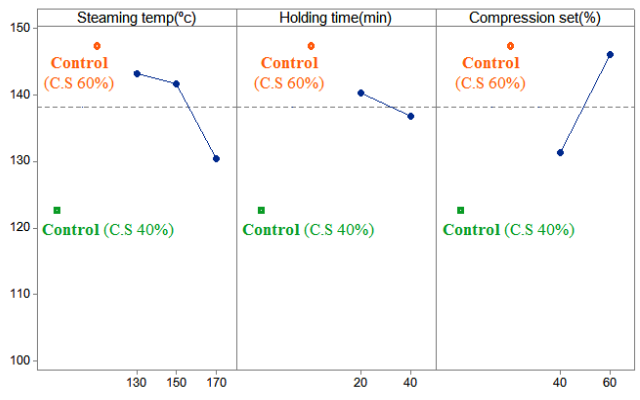

b

Figure 3. Effects of CHTMT treatment process parameters on radial water absorption of wood after $24 \mathrm{~h}(\mathrm{a})$ and $72 \mathrm{~h}(\mathrm{~b})$ of soaking in water.

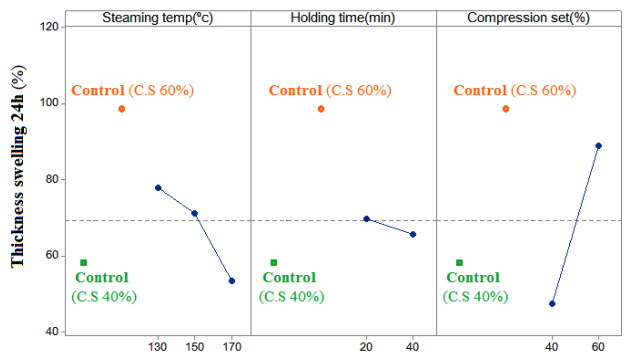

a

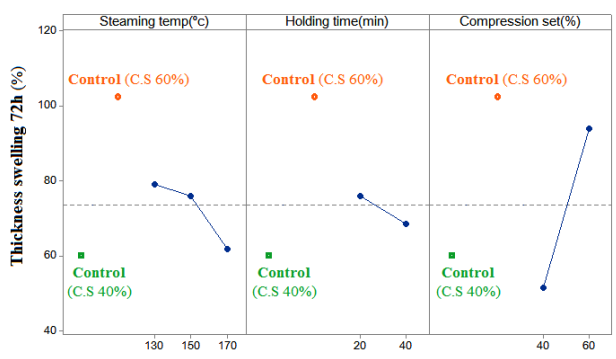

$\mathbf{b}$

Figure 4. Effects of CHTMT treatment process parameters on radial swelling wood after 24h (a) and $72 \mathrm{~h}(\mathrm{~b})$ of soaking in water.

\section{Springback}

The springback of the CHTMT treated wood and the untreated densified wood was determined immediately after densification and also 4 weeks after densification. The springback of the CHTMT treated wood was reduced by the hygrothermal treatment parameters, temperature and holding time (Figure 5). As shown, influence of the treatment temperature was greater than the holding time. By increase of the compressions set, the springback was also increased in both untreated densified wood as well as the CHTMT densified samples (Figure 5). However, the amount of the springback for the CHTMT densified wood with the C.S. of $60 \%$ was less than that of the untreated samples as shown in Figure 5. It was also obtained from the results that the greater amounts of the springback were occurred immediately after the densification process (Figure 5a); while, the later springback after 4 weeks was less than that of the densification step after pressing (Figure 5b). The CHTMT wood showed less springback immediately after the pressing step; while it was great for the untreated samples (Figure 5a).

According to the results, it can be understood that the hygrothermal treatment had an effective role in springback reduction. In fact, chemical structure alteration of the wood cell wall polymers; such as hemicelluloses degradation, increased cellulose crystallinity, cross-linking in lignin structure, and also its hydrophobicity are the reasons for springback reduction according to the reports (Mohebby and Sanaei 2005, Hakkou et al. 2005, Alvira et al. 2010, Navi and Sandberg 2011). 


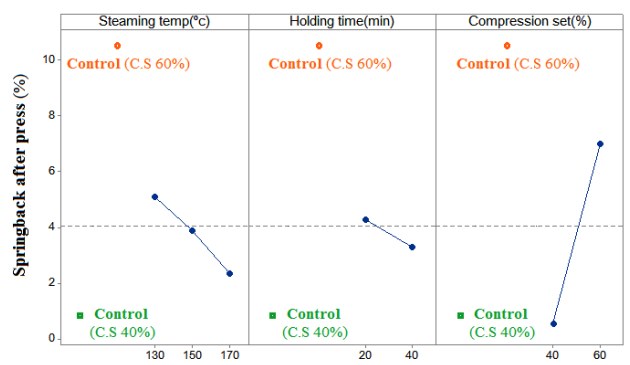

a

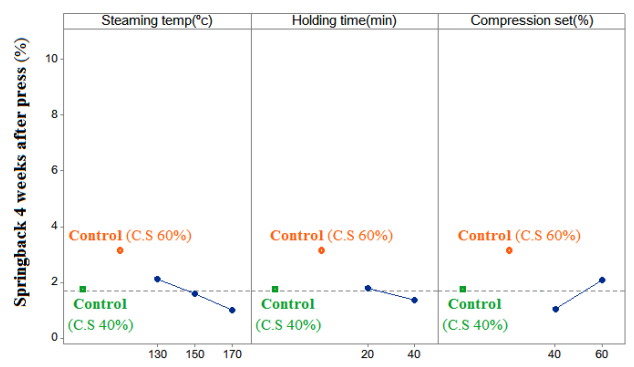

b

Figure 5. Effects of CHTMT treatment process parameters on springback of wood after press (a) and 4 weeks after densification (b).

\section{Mechanical properties}

\section{MOR and MOE}

Any increase of the treatment temperature as well as the holding time reduced the bending modulus of rupture in the hygrothermally treated wood (Figure 6). According to the results shown in Figure 7, densification of the untreated samples increased the MOR. However, it was not correlated with the densification amount. As shown in Figure 7, the MOR of the untreated densified wood with C.S. of $40 \%$ is more than that of the compressed one with C.S. of $60 \%$. Anyhow, the densification increases the MOR in comparison with the control poplar samples. In the CHTMT wood, increase of the hygrothermal treatment temperature showed different effects on the MOR (Figure 7). As shown, the MOR increases up to temperature $150^{\circ} \mathrm{C}$ and then there is reduction at treatment temperature of $170^{\circ} \mathrm{C}$. In general, for the CHTMT wood, the MOR was less than that of the untreated densified wood with C.S. of $40 \%$. The holding time had no significant effects on the MOR for the CHTMT wood (Figure 7). Similar to the untreated densified wood, increase of the densification had reducing effect on the MOR of the CHTMT densified wood. Anyhow, the much the MOR was determined in the densified CHTMT wood as well as the untreated one in comparison with the control poplar samples (Figure 7).

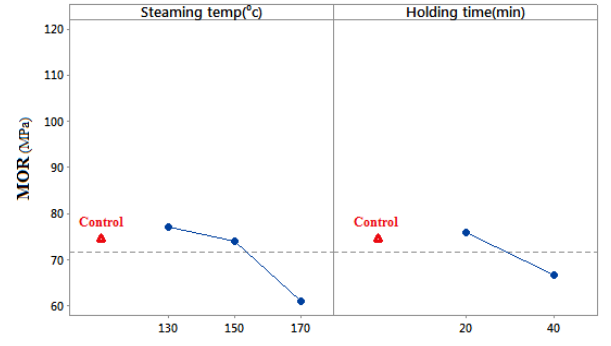

Figure 6. Main effect of hygrothermal treatment temperature on MOR in HTT process.

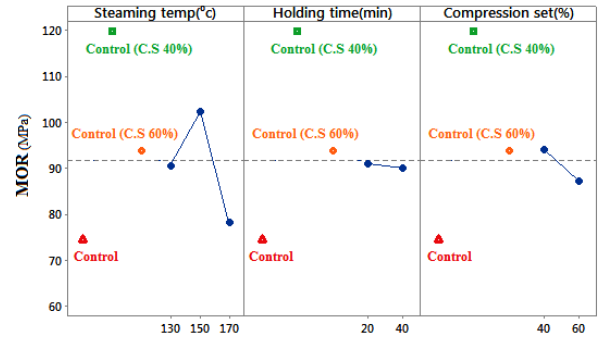

Figure 7. Main effect of hygrothermal treatment temperature on MOR in CHTMT process. 
The bending modulus of the elasticity (MOE) of wood was slightly increased by the hygrothermal treatment temperature as well as the holding time in the HTT wood (Figure 8). The treatment temperature had slight varying effect on the MOE. Results revealed that the MOE was increased due to the densification process in all untreated densified wood as well as the CHTMT compressed wood in comparison with the control poplar wood samples (Figure 9). As shown, the hygrothermal treatment temperature caused increase of the MOE in the CHTMT densified wood (Figure 9). By increase of the hygrothermal treatment temperature, the MOE was increased in the CHTMT densified wood. The MOE was greater than that of the untreated densified wood with C.S. of $60 \%$ and less than that of the C.S. of $40 \%$ (Figure 9). There was a slight increasing MOE in the CHTMT densified wood due to the holding time. Increase of the compression set followed by reduction of the MOE in the CHTMT densified wood. It was similar for the untreated densified wood. As shown, the much the MOE was determined in the untreated densified wood with C.S. $40 \%$ in comparison with the C.S. $60 \%$.

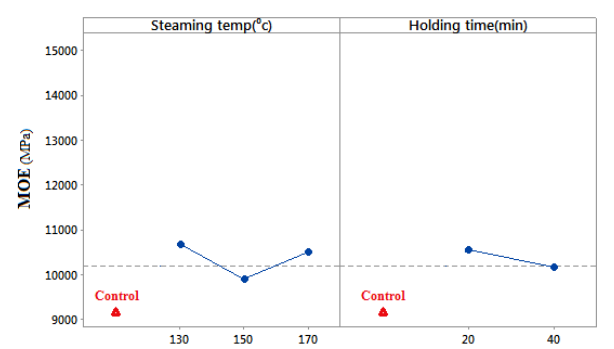

Figure 8. Main effect of hygrothermal treatment temperature on MOE in HTT process.

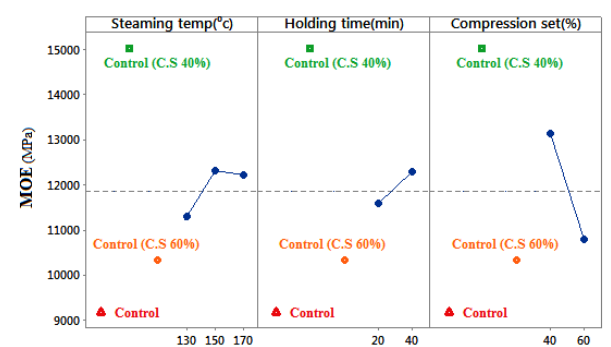

Figure 9. Main effect of hygrothermal treatment temperature on MOE in CHTMT process.

\section{Shear strength parallel to grain}

Results revealed that the shear strength parallel to grain was drastically reduced in the CHTMT densified wood samples due to the hygrothermal treatment temperature, the holding time as well as the compression set (Figure 10). In comparison with the control poplar wood samples as well as the untreated densified wood, the CHTMT wood achieved to lesser amounts of the shear strength parallel to grain. Densification of the untreated wood could increase this strength for the compression set of $40 \%$; while there was a drastic reduction for the samples with C.S. $60 \%$ to lower than that of the control samples (Figure 10). The reduction for the CHTMT wood samples was greater than that of the untreated densified wood. It seems that densification of the wood samples in all cases had limitations for the shear strength. The severe reduction of the shear strength in the CHTMT wood might be related to brittle structure of the treated samples (Mohebby and Sanaei 2005) which is affected by pressure force during the densification step. The brittle cell wall structures might not be able to tolerate the pressure load from the press and became crushed. As shown above, the MOE of the treated wood was increased due to the hygrothermal treatment. It means that the wood became more stiff material and it has lost its elastic property after the treatment which is not be able to behave as an elastic material under press. From results above, not only increase of the densification percentages did not improve the mechanical properties in the CHTMT densified wood; but also it caused severe reduction of those properties. This might be related to less compressibility of the treated wood due to increase of the MOE. Previous works also confirmed the brittle structure of wood due to the hydrothermal or thermal wood modification processes (Mohebby and Sanaei 2005). In fact, reduction of the mechanical properties at high temperatures is due to brittleness of the lignin polymer as well as the cleaved cellulose polymer chains (Mohebby and Sanaei 2005). 


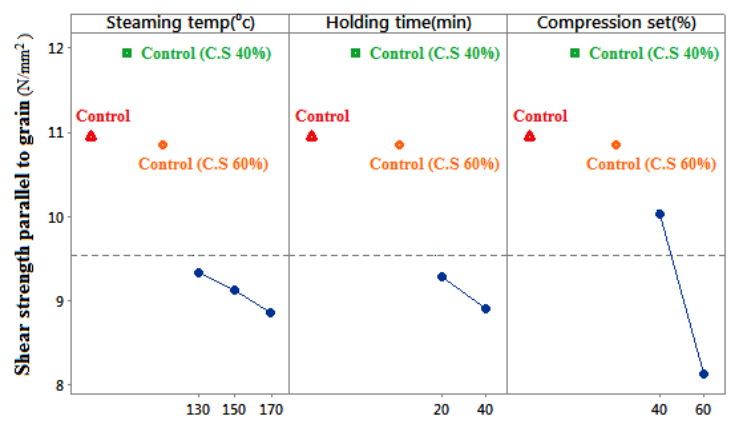

Figure 10. Main effect of compression set on shear strength parallel to grain in CHTMT process.

\section{CONCLUSIONS}

This research was aimed to study any influences of the hygrothermal treatment (HTT) as well as the hygrothermo-mechanical treatment (CHTMT) on wood properties. The following are results withdrawn from the data which were obtained in the current research work:

The hygrothermal treatment reduces the wood density; while it is increased due to the hygrothermo-mechanical process.

The CHTMT densified wood became more water repellent due to the treatment; specially the treatment temperature.

The CHTMT wood is more dimensionally stable.

The springback is reduced due to the CHTMT densification process.

The hygrothermal treatment reduces the bending modulus of rupture; while the hygrothermomechanical process improves this property to higher levels. However, both processing techniques increase the bending modulus of elasticity.

There is a drastic loss of the shear strength of wood for CHTMT densified wood; especially by increase of the densification.

\section{REFERENCES}

Alvira, P.; Tomas-Pejo, E.; Ballesteros, M.; Negro, M.J. 2010. Pretreatment technologies for an efficient bioethanol production process based on enzymatic hydrolysis. A Review. Bioresour Technol 101: 4851-4861.

Anshari, B.; Guan, Z.W.; Kitamori, A.; Jung, K.; Hassel, I.; Komatsu, K. 2011. Mechanical and moisture-dependent swelling properties of compressed japanese cedar. Construction and Building Materials 25: 1718-1725.

Assor, C.; Placet, V.; Chabbert, B.; Habrant, A.; Lapierre, C.; Pollet, B.; Perre, P. 2009. Concomitant changes in viscoelasticity properties and amorphous polymers during the hydrothermal treatment of hardwood and softwood. J Agric Food Chem 57: 6830-6837. 
American Society for Testing of Materials. ASTM. 2014. Standard methods of testing small clear specimens of timber. ASTM D 143-09.

Biswas, A.K.; Yang, W.; Blasiak, W. 2011. Steam pretreatment of salix to upgrade biomass fuel for wood pellet production. Fuel Process Technol 92: 1711-1717.

Blomberg, J. 2005. Elastic strain at semi-isostatic compression of scots pine (Pinus sylvestris). $J$ Wood Sci 51: 401-404.

Boonstra, M.J.; Tjeerdsma, B. 2006. Chemical analysis of heat treated softwoods. Holz Roh Werkst 64: 204-211.

Boonstra, M.J.; Blomberg, J. 2007. Semi-isostatic densification of heat-treated radiate pine. Wood Sci Technol 41: 607-617.

Boonstra, M.J.; Vanacker, J.; Kegel, E.; Stevens, M. 2007. Optimization of a two-stage heat treatment process: durability aspects. Wood Sci Technol 41: 31-57.

Dwainto, W.; Inoue, M.; Norimoto, M. 1997. Fixation of compressive deformation of wood by heat treatment. Makuzai Gakkaishi 43(4): 303-309.

Dwianto, W.; Morooka, T.; Norimoto, M.; Kitajima, T. 1999. Stress selaxation of sugi (Cryptomeria japonica D. Don) wood in radial compression under high temperature steam. Holzforschung 53: 541-546.

Esteves, B.; Marques, A.V.; Domingos, I.; Pereira, H. 2007. Influence of steam on the properties of pine (Pinus pinaster) and eucalypt (Eucalyptus globulus) wood. Wood Sci Technol 41: 193-207.

Fukuta, S.; Takasu, Y.; Sasaki, Y.; Hirashima, Y. 2007. Compressive deformation process of Japanese cedar (Cryptomeria japonica). Wood Fiber Sci 39: 548-555.

Garrote, G.; Domínguez, H.; Parajó, J.C. 1999. Hydrothermal processing of lignocellulosic materials. Holz Roh Werkst 57: 191-202.

Gong, M.; Lamason, C.; LI, L. 2010. Interactive effect of surface densification and post-heattreatment on aspen wood. Journal of Materials Processing Technol 210: 293-296.

Hakkou, M.; Pétrissans, M.; Zoulalian, A.; Gérardin, P. 2005. Investigation of wood wetability changes during heat treatment on the basis of chemical analysis. Polymer Degradation and Stability 89: $1-5$.

Hillis, W.E. 1984. High temperature and chemical effects on wood stability. Part 1: General Considerations. Wood Sci Technol 18: 281-293.

Hsu, W.E.; Schwald, W.; Schwald, J.; Shields, J.A. 1988. Chemical and physical changes required for producing dimensionally stable wood-based composites. Wood Sci Technol 22: 281-289.

Inoue, M.; Norimoto, M.; Tanahashi, M.; Rowell, M.R. 1993. Steam or heat fixation of compressed wood. Wood Fiber Sci 25 (3): 224-235.

Ito, Y.; Tanahashi, M.; Shigematsu, M.; Shinoda, Y.; Ohta, C. 1998. Compressive-molding of wood by high-pressure steam-treatment. Part 1: Development of compressively molded squares from thinning. Holzforschung 52: 211-216.

Kutnar, A.; Kamke, F.A.; Petri, M.; Sernek, M. 2008. The influence of viscoelastic thermal compression on the chemistry and surface energetics of wood. Colloids and Surfaces A: Physicochem Eng Aspects 329: 82-86.

Lam, P.S. 2011. Steam explosion of biomass to produce durable pellet. Ph.D. Dissertation, The University of British Columbia, Vancouver, Canada.

Lam, P.S.; Sokhansanj, S.; Bi, X.; Lim, C.J.; Melin, S. 2011. Energy input and quality of pellets 
made from steam exploded douglas fir (Pseudotsuga menziesii). Energy Fuel 25: 1521-1528.

Liu, S. 2008. A kinetic model on autocatalytic reactions in woody biomass hydrolysis. $J$ Biobased Mater Bio 2: 135-147.

Metsa-Kortelainen, S.; Antikainen, T.; Viitaniemi, P. 2006. The water absorption of sapwood and heartwood of scots pine and norway spruce heat-treated at $170^{\circ} \mathrm{C}, 190^{\circ} \mathrm{C}, 210^{\circ} \mathrm{C}$ and $230^{\circ} \mathrm{C}$. $\mathrm{Holz}$ Roh Werkst 64 (3): 192-197.

Mirzaei, G.; Mohebby, B.; Tasooji, M. 2012. The effect of hydrothermal treatment on bond shear strength of beech wood. European Journal of Wood and Wood Products 70: 705-709.

Mohebby, B.; Sanaei, I. 2005. Influences of the hydro-thermal treatment on physical properties of beech wood (Fagus orientalis). The international research group on wood protection(IRG). $36^{\text {th }}$ Annual Meeting, Bangalore, India 24 - 28 April, IRG Document No. IRG/WP 05-40303.

Mohebby, B.; Sharifinia-Dizboni, H.; Kazemi-Najafi, S. 2009. Combined hydro-thermomechanical modification (CHTM) as an innovation in mechanical wood modification. In: Proceeding of $4^{\text {th }}$ European Conference on Wood Modification (ECWM4). Stockholm, Sweden, 353-360.

Navi, P.; Girardet, F. 2000. Effects of thermo-hydro-mechanical treatment on the structure and properties of wood. Holzforschung 54: 287-293.

Navi, P.; Heger, F. 2004. Combined densification and thermo-hydro-mechanical processing of wood. MRS Bull 29: 332-336.

Navi, P.; Sandberg, D. 2011. Thermo-hydro-mechanical processing of wood. Engineering Sciences $360 \mathrm{p}$.

Popescu, C.M.; Popescu, M.C. 2013. A near infrared spectroscopic study of the structural modifications of lime (Tilia cordata Mill.) wood during hydro-thermal treatment. Spectrochimica Acta Part A: Molecular and Biomolecular Spectroscopy 115: 227-233.

Ramos, L.P. 2003. The chemistry involved in the steam pretreatment of lignocellulosic materials. Quim Nova 26: 863-871.

Stamm, A.J. 1964. Wood and cellulose science. New York: Ronald Press p. 549.

Tjeerdsma, B.F.; Militz, H. 2005. Chemical changes in hydrothermal treated wood. FTIR analysis of combined hydro thermal and dry heat-treated wood. Holz Roh Werkst 63 (2): 102-111.

Welzbacher, C.R.; Wehsener, J.; Rapp, A.O.; Haller, P. 2008. Thermo-mechanical densification combined with thermal modification of Norway spruce (Picea abies Karst) in industrial scaledimensional stability and durability aspects. Holz Roh Werkst 66: 39-49. 